\title{
Actividades del Departamento de Bellas Artes
}

\author{
Por Héctor García Valerio, hector.valerio@gmail.com \\ Nadia Guadalupe Ruelas Ramírez, nadiaruelas95@gmail.com, \\ Zaira Imelda León Salguero, zaira.leonsa@gmail.com \\ Estudiantes de VIII semestre de la Licenciatura en Artes Plásticas
}

El año comenzó, al igual que las actividades en la Universidad de Sonora y el Departamento de Bellas Artes. Enero nos brinda uno de los eventos culturales con más presencia en el estado de Sonora, El Festival Alfonso Ortiz Tirado, y en él, la Universidad de Sonora se hace partícipe a través de algunos artistas que se presentan y hacen posible el festival, entre ellos maestros de nuestra institución, alumnos y sobre todo egresados.

Las instalaciones de la División de Humanidades y Bellas Artes se muestran vivas, los pasillos envuelven ensayos de algunos estudiantes de escénicas o música, incluso trabajos de las licenciaturas de Arquitectura y Diseño y Artes Plásticas, también exposiciones itinerantes como Pinocho que muestra una réplica de pinturas realizadas por Toledo sobre la obra literaria, además de otras exposiciones en el Centro de las Artes, como lo fueron 13 miembros para Látex, y diversas muestras académicas al concluir los Talleres Libres y las clases del semestre de la Licenciatura en Artes Plásticas, dentro de espacios como Galería Manuel Romo Rodríguez y Sociedad de Artesanos Hidalgo que también abrió sus

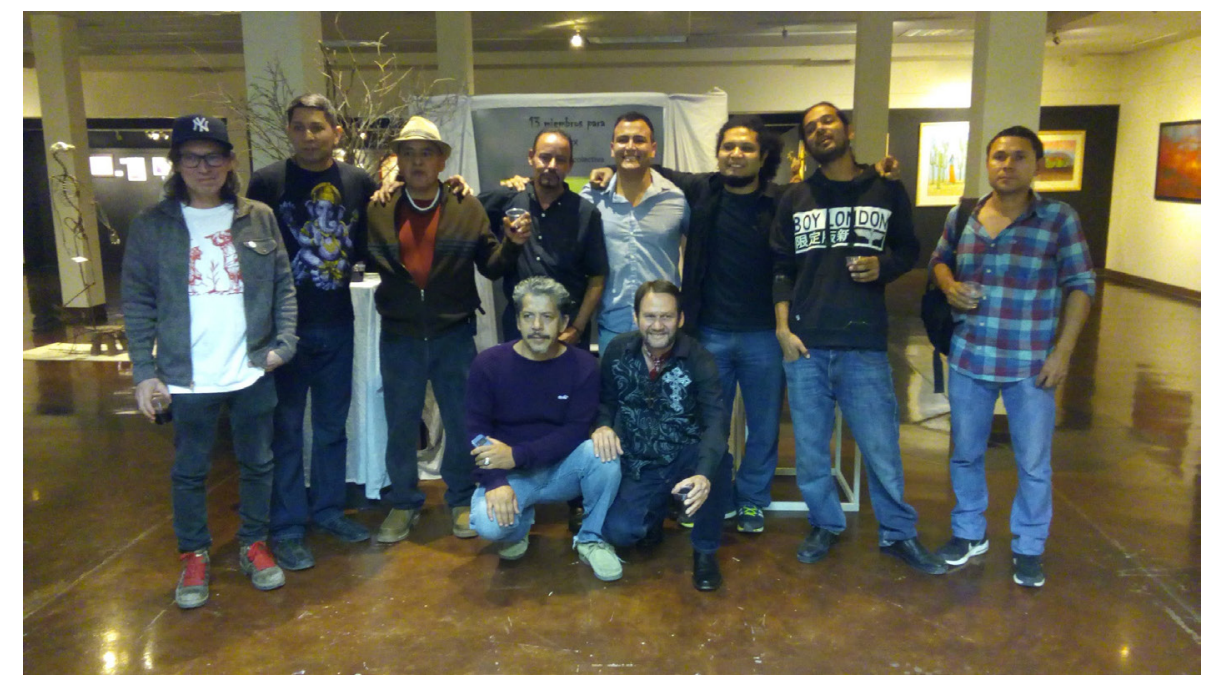

Exposición: 13 miembros para el látex. foto: Samuel Sanchez. 


\section{DEL ESTUDIANTADO}

puertas en exposiciones como Taller de Producción para exhibir los trabajos que realizan los alumnos próximos a egresar y así apreciar las diferentes técnicas que se manejan en pintura, escultura y grabado. En la Galería Estudio Ozuna también se presentaron los eventos Pigmalión, exposición colectiva de esculturas donde participaron alumnos y egresados de la Licenciatura en Artes con especialidad en escultura, y Policromías del artista Plástico Fernando Peñuelas.

La realización de eventos artísticos y culturales por parte de las escuelas que componen el Departamento de Bellas Artes es amplia y variada. La Licenciatura en Artes Escénicas tuvo mucha actividad desde puestas en escena de sus egresados como lo fueron, Te juro Juana que tengo ganas en marzo, así como también Ejecutor 14 de Adel Hakim presentada en el Foro de Bellas Artes, los alumnos estudiantes del $1 \mathrm{~V}$ semestre de actuación participaron con la obra titulada Las entretelas del corazón, otros alumnos que también se presentaron fueron los del V1ll semestre de Laboratorio de puesta en escena 11 con Polo pelota amarilla. También se realizó teatro para niños en el Kiosco del Arte, bajo la producción de Teatro Breve donde se presentaron obras como Alienígena, La Invasión y Quién manda en Luegocity. En la tercera celebración del día del títere en marzo se presentó Leyendas del pueblo del Valle y el día 30 de abril estuvieron las obras La familia de Frankenstein, Alicia en el país de las maravillas y Pinocho, estas dos últimas se presentaron en el Parque Infantil.

Por parte de Artes Escénicas opción Danza, se tuvo la participación de los alumnos del VI semestre con las presentaciones de Mares de Arena, XY, bajo la dirección del Maestro David Barrón, además de la obra en proceso Kraken archivos de la ciudad, con la producción de Adriana Castaños y Emmanuel Pacheco.

En marzo el 5to Foro Xunuta, Capítulos de Sonora brindó su espacio para el diálogo sobre temas regionales, entre los cuales el maestro grabador Adán Romero Valencia presentó la ponencia titulada Tribus urbanas, y la estudiante de la Licenciatura en Artes Plásticas Claudia Azpilcueta, ponencia Sangre menstrual como opción en la pintura. Otros Artistas como Roberto Carretas presentó su proyecto 13:20 Libros de la noche y el día. Tomo VII, y el fotógrafo Wegner Segarra dió su charla sobre la colección Los Vaqueros de la Cruz del Diablo. Además dentro del marco de este mismo evento se montó una exposición colectiva de obra plástica, en la 


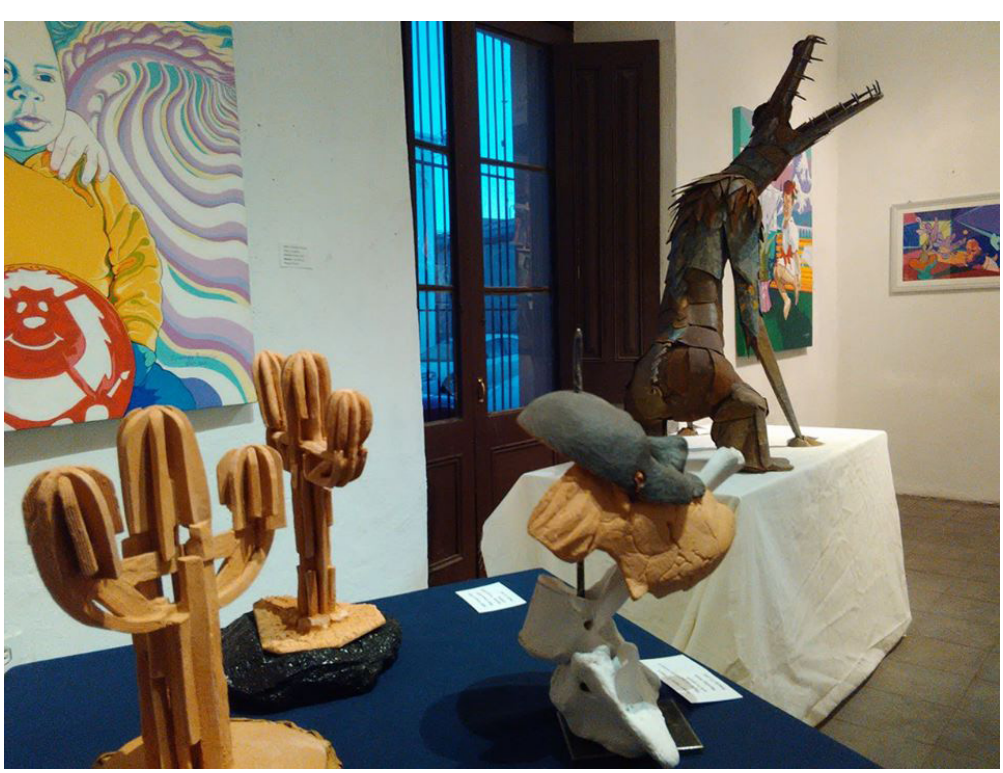

Foto: Dalila Mar. Exposición: Pigmalion
Sala Leo Sandoval, donde se lleva a cabo el Foro.

La Licenciatura

en Música nos

deleitó con los ya conocidos Viernes de Concierto en manos de sus estudiantes. Otros de los eventos que permitieron disfrutar de este arte fueron, el concierto de la Orquesta de Guitarras de Sonora dentro del VIII Festival de Primavera 2018 y el concierto homenaje Emiliana de Zubeldía y la Guitarra Clásica a 31 años de su partida, ejecutando el estreno mundial de su obra para guitarra a cargo del concertista Erick Quijada, quien también participó en la Temporada 3 de Músicos Trabajando A.C.

Las Artes en las Letras estuvieron presentes este 2018 en el Departamento de Letras y Lingüística donde se presentaron Amorosos Amorales, En la Boca del Lobo, Petición de Mano y Roma al Final de la Vía.

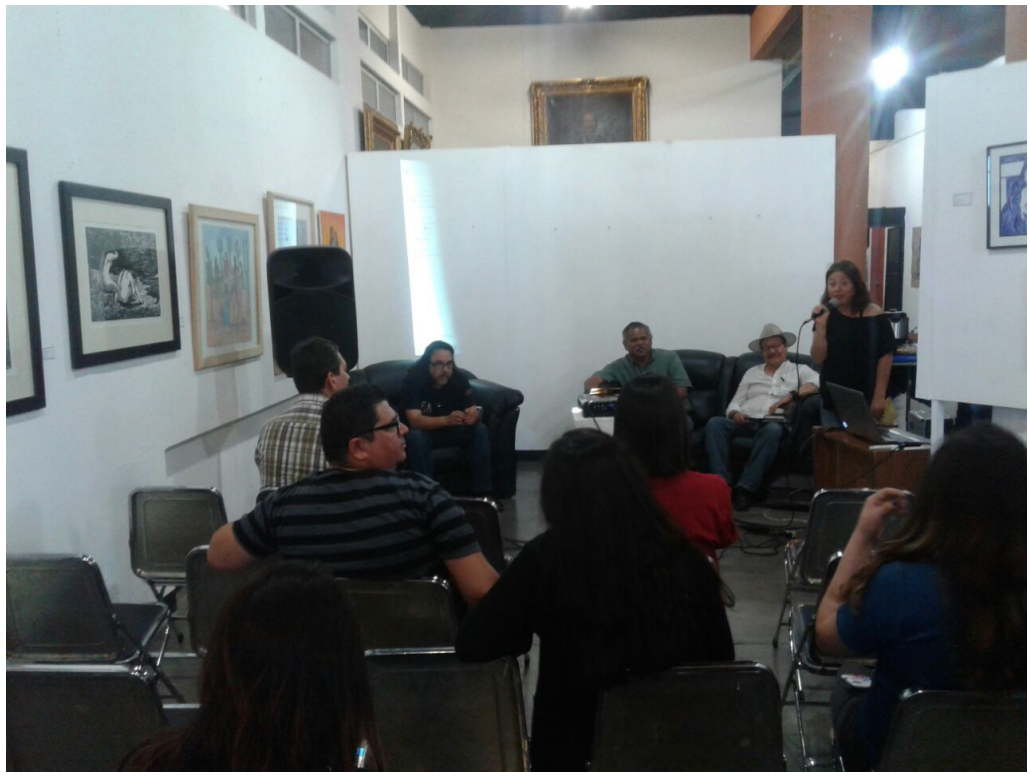

Foto: David Hernandez. Evento: foro Xunuta
Otras actividades que se llevaron a cabo fuera de las instalaciones de la Universidad, llegando así no solo a nuestra c o m u n i d a d universitaria, eventos como el encuentro de la cerveza y jazz 
Foto: Nadia Ruelas, Exposición Taller de Producción

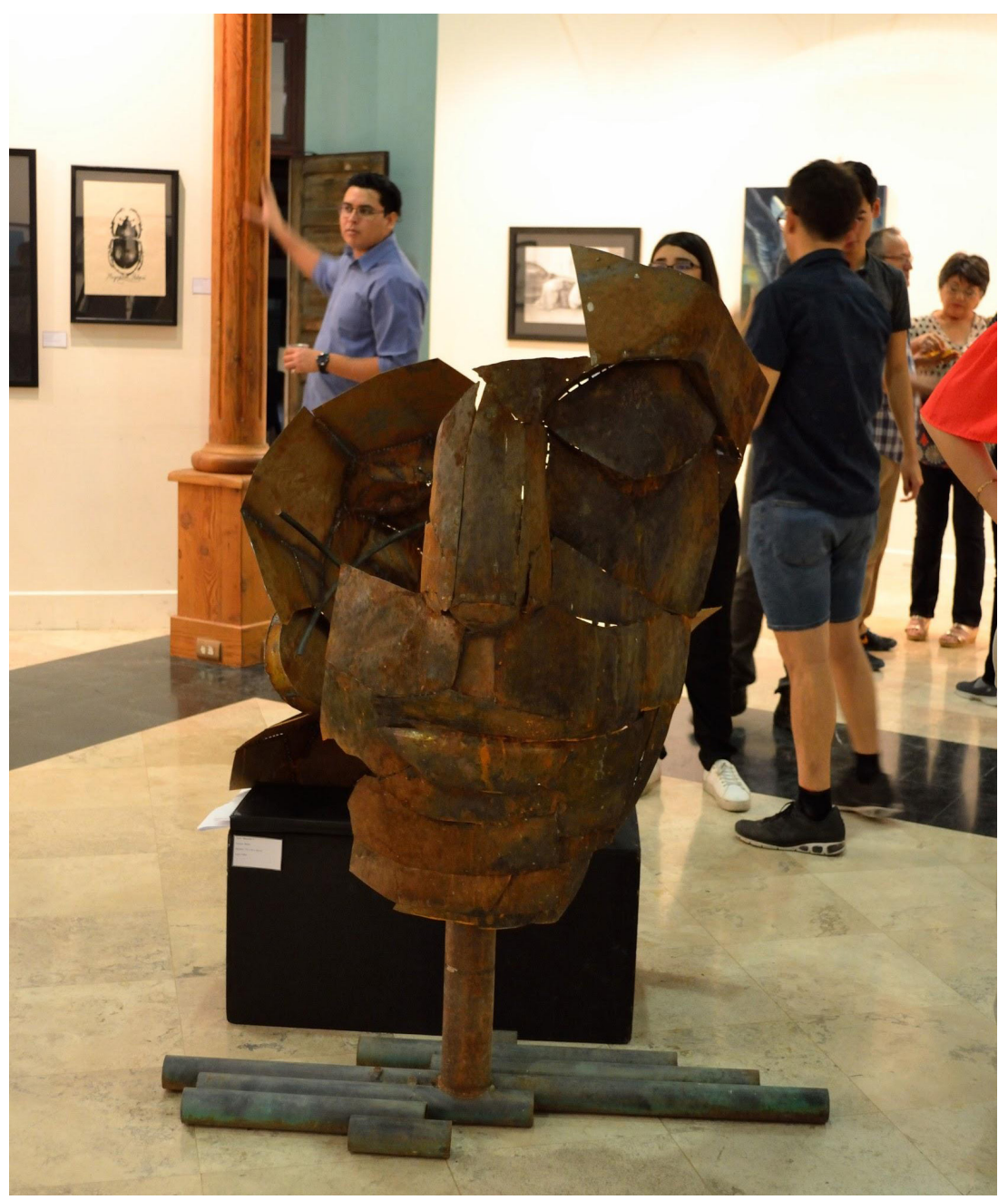

que se llevó a cabo en el parque La Ruina donde pudimos escuchar un concierto de piano del maestro Alejandro Corona al aire libre y a Paloma Ledgard \& Hermosillo Jazz Sexteto y León Lugo trío, grupos integrados por alumnos y egresados de la Licenciatura en Música.

Artes Plásticas también tuvo participación fuera de las instalaciones, el 26 de febrero en Casa Madrid, Wenceslao Meneses presentó una exposición titulada "Atardeceres Tóxicos" como invitado para celebrar la reapertura del lugar.

El semestre ya terminó y fue un ciclo lleno de actividades artísticas, pues mientras avanzaba, la preparación de los alumnos iba a la par, adquiriendo nuevos conocimientos y habilidades, aquello que se va creando, ha de ser visto y el conocimiento adquirido en el aula suele ser distinto al obtenido en "escena" o expuesto al público. El Arte pues, hay que vivirlo. Finalmente, debemos decir que ha resultado bastante interesante la oportunidad de estar en contacto con las otras Artes, pues van de la mano y se complementan. 


\section{(Arte)}

\section{DEL ESTUDIANTADO}

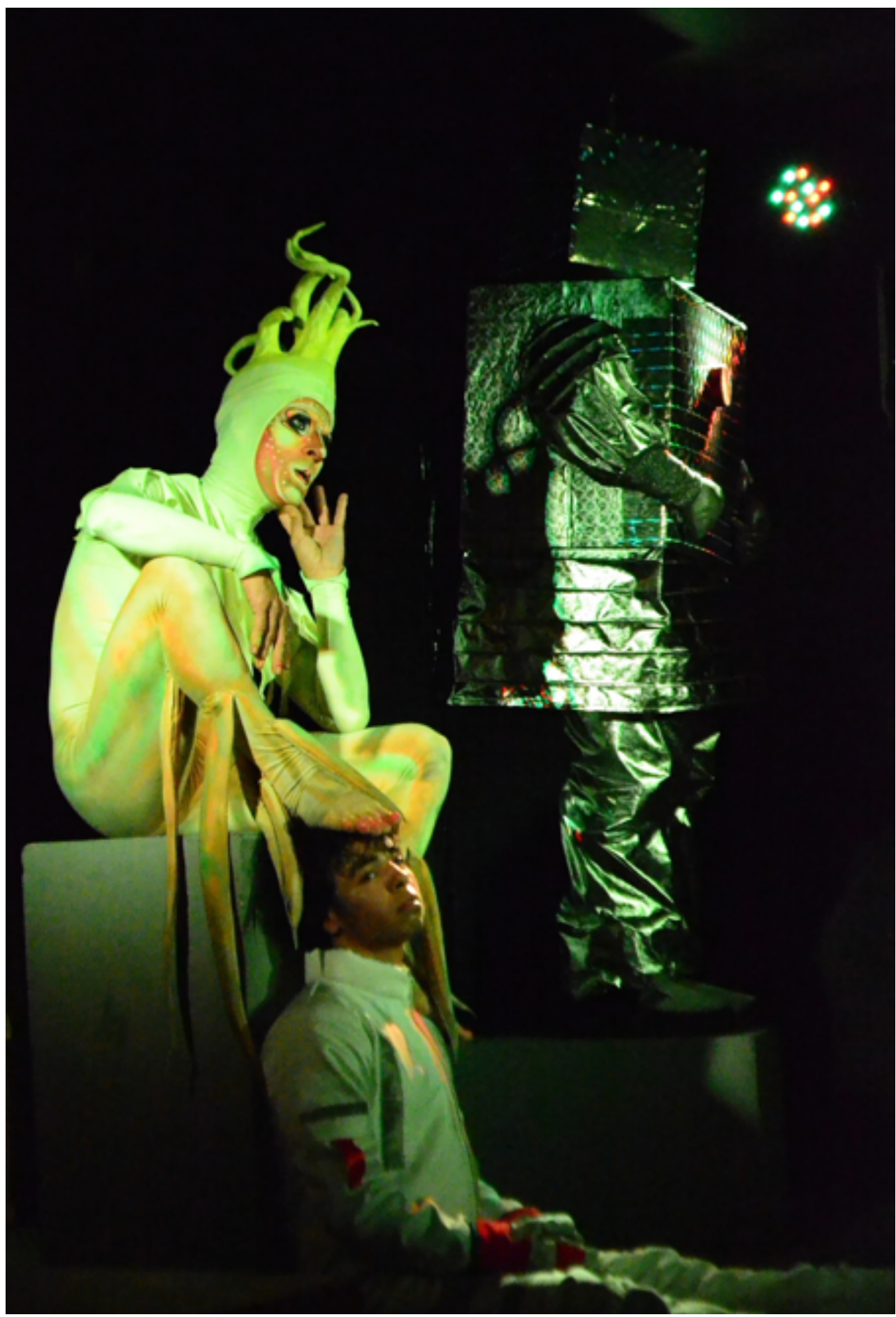

Alienígena, Teatro Breve Kiosco del Arte 